УДК 373+612.776.1

\title{
ВЛИЯНИЕ ФАКТОРА «ПЕРИОДИЧНОСТЬ ЗАНЯТИЙ» ФИЗИЧЕСКИМИ УПРАЖНЕНИЯМИ \\ НА ФУНКЦИОНАЛЬНОЕ СОСТОЯНИЕ ДЕТЕЙ 5-6 ЛЕТ ПРИ ИНФОРМАЦИОННЫХ НАГРУЗКАХ
}

\author{
Чернова Мария Борисовна \\ кандидат педагогических наук, доцент \\ ФГБНУ «Институт возрастной физиологии» \\ Российской академии образования \\ Зайцева Галина Алексеевна \\ кандидат педагогических наук, доцент; \\ ФГАОУВО «Национальный исследовательский \\ технологический университет «МИСиС»
}

Васильева Римма Михайловна кандидат биологических наук, старший научный сотрудник Орлова Нина Исааковна кандидат биологических наук, старший научный сотрудник ФГБНУ «Институт возрастной физиологии» Российской академии образования

\begin{abstract}
Аннотация. В ходе исследования установлено, что выполнение одинакового объема физической нагрузки высокой интенсивности, равномерно распределенного между 3 и 6 занятиями в неделю, в целом обеспечивают сходное позитивное воздействие на функциональное состояние детей 5-6 лет в условиях относительного покоя и при напряженной информационной нагрузке. Выявлена слабая тенденция более значительных изменений некоторых из рассматриваемых показателей в условиях шестиразовых занятий по сравнению с трехразовыми, что может быть следствием неодинакового общего объема занятий.

Ключевые слова: физическая нагрузка, частота занятий, интенсивность, объем, функциональное состояние, информационная нагрузка.
\end{abstract}




\title{
INFLUENCE OF THE FACTOR "FREQUENCY OF PHYSICAL TRAINING" ON THE FUNCTIONAL STATE OF 5-6 YEAR OLD CHILDREN UNDER INFORMATION LOADS
}

\author{
Chernova Maria Borisovna \\ $\mathrm{PhD}$ (Cand. Ped. Sci.), assistant professor \\ The Federal State Budget Scientific Institution \\ «Institute of Developmental Physiology of the \\ Russian Academy of Education» \\ Zaytseva Galina Alekseevna \\ $\mathrm{PhD}$ (Cand. Ped. Sci.), associate professor \\ National University of Science and Technology «MISiS» \\ Vasilieva Rimma Mikhailovna \\ $\mathrm{PhD}$ (Cand. Biol. Sci.), senior research officer \\ Orlova Nina Isaakovna \\ $\mathrm{PhD}$ (Cand. Biol. Sci.), senior research officer \\ The Federal State Budget Scientific Institution \\ «Institute of Developmental Physiology of the \\ Russian Academy of Education»
}

\begin{abstract}
The study established that the same volume of high-intensity physical activity evenly distributed between 3 or 6 sessions per week generally provides similar benefits for the functional state of 5-6-year-old children under conditions of relative rest and information overload. There was a weak tendency towards more significant changes in some of the studied parameters for six sessions per week in comparison with three sessions per week, which may be due to unequal total exercise volume.
\end{abstract}

Key words: physical activity, frequency of sessions, intensity, volume, functional state, information load.

Сегодня в сфере оздоровительной физической культуры нерешенным остается вопрос о рациональной периодичности занятий оздоровительной направленности применительно к фиксированному объему нагрузки определенной интенсивности $[11,12,13]$. В практическом отношении весьма важной является задача рационального размещения эффективного объема 


\section{МОДЕРНИЗАЦИЯ СОВРЕМЕННОГО ОБРАЗОВАНИЯ: АНАЛИЗ ОПЬТА И ТЕНДЕНЦИЙ}

нагрузки в рамках недельного цикла оздоровительной тренировки [5, 12, 4 и др.]. В имеющейся литературе недостаточно сведений о влиянии одного и того же объема нагрузки, по-разному распределенного в недельном цикле занятий, на величину долговременного функционального эффекта. Не ясно, можно ли обеспечить схожий функциональный эффект при разном количестве занятий на фоне сохранения одинакового объема работы.

Цель исследования - оценить влияние разной периодичности занятий физическими упражнениями на функциональное состояние детей 5-6 лет при сохранении неизменным недельного объема нагрузки высокой интенсивности.

\section{Методика}

В исследовании принимали участие практически здоровые дети 5-6 лет $(\mathrm{n}=89)$. Сопоставлялась эффективность 3 и 6-разовых занятий физическими упражнениями в неделю. В каждом занятии использовались экспериментальные комплексы интенсивностью 70-80 \% максимального пульсового резерва (МПР) и продолжительностью 20 и 10 минут. Недельный объем экспериментальной нагрузки при этом был одинаковым и составлял 60 минут. По составу используемых средств физической подготовки комплексы были идентичными, но различались по времени их выполнения в одном занятии. Были сформированы 2 экспериментальные и 1 контрольная группы. Группа I выполняла комплексы упражнений длительностью 20 минут 3 раза в неделю, группа II - 10 минут, 6 раз в неделю. Продолжительность исследования превысила 30 недель.

Временной анализ вариабельности сердечного ритма осуществлялся на базе автоматизированного комплекса по методике, предложенной Р.М. Баевским. Определяли частоту сердечных сокращений (ЧСС), разброс кардиоинтервалов (MxDMn), среднеквадратическое отклонение (SDNN), среднюю продолжительность кардиоинтервалов (RRNN), моду (Mo), амплитуду моды (АМо), стресс-индекс (SI).

Систолическое (СД) и диастолическое (ДД) давление крови регистрировали по тонам Короткова в соответствии с рекомендациями ВОЗ. Применяли механический тонометр и детскую манжету, соответствующую возрасту. Рассчитывали пульсовое давление (ПД), двойное произведение (ДП), среднее давление (САД), вегетативный индекс Кердо (ВИК).

Информационная нагрузка задавалась с помощью фигурных таблиц. Перед выполнением первого задания испытуемым сообщалось, что они 


\section{МОДЕРНИЗАЦИЯ СОВРЕМЕННОГО ОБРАЗОВАНИЯ: АНАЛИЗ ОПЬТА И ТЕНДЕНЦИЙ}

должны работать в удобном для себя темпе (автотемп), а перед реализацией второго - вводилась инструкция, содержащая требование работать с максимально возможной скоростью (максимальный темп) [3]. Рассчитывалась скорость (количество просмотренных знаков - А) и продуктивность (коэффициент Q) работы при тестировании в лаборатории и в дошкольном образовательном учреждении до ( $\left.\mathrm{A}_{д о}, \mathrm{Q}_{д о}\right)$ и после ( $\mathrm{A}_{\text {после, }}$ Qпосле) занятий. Оценивали эффективность деятельности посредством определения соотношений: А/ЧCC, A/SI, A/ДП, Q/ЧCC, Q/SI, Q/ДП [3].

На основе проективной методики Р.Тэммл «Выбери нужное лицо» в модификации Р.В. Овчаровой определяли индекс тревожности (ИТ), восьмицветового теста М. Люшера в модификации Л.Н. Собчик коэффициент вегетативного тонуса (КВТ) и ситуативную тревожность (СТ).

Для обработки полученных данных использовали пакет прикладных программ Microsoft Excel и Statistica 6.0. Значимость различий определяли на основе расчета параметрических и непараметрических критериев для связанных и независимых выборочных совокупностей.

\section{Результаты исследования и их обсуждение}

Анализ полученных результатов показал, что, в экспериментальной группе (ЭГІ), применяющей программу трехразовых занятий (величина тренирующей нагрузки в одном занятии - 20 минут), в состоянии покоя отмечались существенные $(\mathrm{p}<0,05-0,001)$ изменения ряда показателей, свидетельствующие об улучшении ФС занимающихся: ЧCC, RRNN, Mo, AMo, SI, ДП, ИТ.

При информационной нагрузке, выполняемой в режиме автотемпа, под влиянием систематических занятий в ЭГІ произошли выраженные ( $<<0,05$ 0,001) изменения ФС: ЧСС, RRNN, Мо, АМо, САД, ДП, ИТ, А, Q, А/ЧСС, A/SI, Q/ЧCC, Q/SI.

При информационной нагрузке, реализуемой в максимальном темпе, в ЭГІ также отмечались благоприятные изменения $(\mathrm{p}<0,05-0,001)$ ряда показателей ФС: ЧСС, RRNN, AMo, SI, СД, САД, ДП, ИТ, А, Q, А/ЧСС, $\mathrm{Q} / \mathrm{YCC}, \mathrm{Q} / \mathrm{SI}$.

B экспериментальной группе (ЭГII), использующей программу шестиразовых занятий (величина высокоинтенсивной нагрузки в одном занятии - 10 минут), в состоянии покоя статистически значимо $(\mathrm{p}<0,05-0,001)$ изменились средние величины RRNN, SI, ДП, КВТ, ИТ. 


\section{МОДЕРНИЗАЦИЯ СОВРЕМЕННОГО ОБРАЗОВАНИЯ: АНАЛИЗ ОПЬТА И ТЕНДЕНЦИЙ}

Приросты изучаемых показателей ФС в ЭГІІ при информационной нагрузке, выполняемой в режиме «автотемп», носили статистически значимый ( $<<0,05-0,001)$ характер и касались RRNN, AMo, ДП, ИТ, А, А/ЧСС, A/SI, А/ДП, Q/ЧСС, Q/SI, Q/ДП.

При информационной нагрузке, реализуемой в максимальном темпе, также произошли существенные $(\mathrm{p}<0,05-0,001)$ приросты изучаемых показателей, свидетельствующие об улучшении ФС занимающихся. Они касались ЧСС, АMo, SI, ДП, КВТ, ИТ, А, А/ЧСС, А/ДП, Q/ЧСС, Q/ДП.

Сравнительный анализ изменений ФС в ЭГ I и ЭГ ІІ показал, что сдвиги большинства исследуемых переменных практически не зависели от кратности занятий при равном недельном объеме нагрузки высокой интенсивности. Различия $(\mathrm{p}<0,05)$ между экспериментальными группами в состоянии покоя обнаружены только в отношении СД и ПД, при работе с комфортной скоростью - А и Q/ЧСС, максимальной скоростью - ПД, А, А/ЧСС.

Проблема выбора оптимальной периодичности занятий физическими упражнениями оздоровительной направленности сохраняет свою актуальность. По-прежнему не ясно как влияет различное распределение одного и того же объема нагрузки на величину долговременного функционального «тренировочного» эффекта. Имеются противоречивые данные об изменениях ФС занимающихся при «фиксированной» недельной величине нагрузки, по разному распределенной в цикле занятий $[2,1,9,6,14$, $10,8,4]$. Вместе с тем необходимо отметить, что в ряде экспериментальных работ наблюдалось сопоставимое влияние нагрузки одинакового объема при разной частоте занятий на ФС и здоровье занимающихся. При сравнении долговременных эффектов одинаковых физических нагрузок, реализуемых за один, два или три отрезка времени, выявлено сходное полезное воздействие на здоровье и физическое состояние $[7,11,12]$. В одной из недавно опубликованных работ показано, что изменения частоты занятий оздоровительной направленности в пределах от 3 до 12 раз в неделю, при сохранении неизменными недельного объема и интенсивности нагрузки, не оказывает существенного влияния на интегральные показатели функционального состояния детей 6-7 лет [4]. При этом все варианты распределения нагрузки в недельном цикле обеспечивают примерно равный прирост показателей функционального состояния. Автор полагает, что сходный кумулятивный эффект оздоровительной тренировки может быть 


\section{МОДЕРНИЗАЦИЯ СОВРЕМЕННОГО ОБРАЗОВАНИЯ: АНАЛИЗ ОПЫТА И ТЕНДЕНЦИЙ}

достигнут при различном распределении в недельном цикле одного и того же объема физической нагрузки высокой интенсивности [4].

\section{Заключение}

В ходе исследования установлено, что выполнение одинакового объема физической нагрузки высокой интенсивности, равномерно распределенного между 3 и 6 занятиями в неделю, в целом обеспечивают сходное позитивное воздействие на функциональное состояние детей 5-6 лет в условиях относительного покоя и при напряженной информационной нагрузке. Выявлена слабая тенденция более значительных изменений некоторых из рассматриваемых показателей в условиях шестиразовых занятий по сравнению с трехразовыми, что может быть следствием неодинакового общего объема занятий. Полученные результаты показывают, что периодичность имеет меньшее значение, чем интенсивность, объем и направленность физической нагрузки.

Исследование выполнено при финансовой поддержке Российского фонда фундаментальных исследований (проект № 19-013-00127).

\section{Список литературы}

1. Вайнбаум, Я.С. Гигиена физического воспитания / Я.С. Вайнбаум. М.: Просвещение, 1986. - 176 с.

2. Виру, А.А. Аэробные упражнения / А.А. Виру, Т. А. Юриямиэ, Т.А. Смирнова. - М.: Физкультура и спорт, 1988. - 142 с.

3. Криволапчук, И.А. Особенности факторной структуры функционального состояния организма мальчиков и девочек 6-7 лет/ И.А. Криволапчук, М.Б. Чернова // Физиология человека. - 2021. - Т. 47. №2. - С. 32-44.

4. Криволапчук, И.А. Частота занятий физическими упражнениями как компонент физической нагрузки у детей 6-7 лет / И.А. Криволапчук // Научнотеоретический журнал «Ученые записки университета имени П.Ф. Лесгафта», 2019. №9. - C. 134-139.

5. Уилмор, Дж. Физиология спорта и двигательной активности / Дж. Уилмор, Д. Костилл. - Киев: Олимпийская литература, 1997. - 504 с.

6. Cornelissen, V.A. Exercise training for blood pressure: a systematic review and meta-analysis / V.A. Cornelissen, N.A. Smart // J Am Heart Assoc. 2013. - Vol. 2, № 1. - P. e004473. 
7. Ebisu, T. Splitting the distance of endurance running: on cardiovascular endurance and blood lipids / T. Ebisu // Jpn J Phys Educ. - 1985. - Vol. 30. - P. $37-43$.

8. Effect of dance therapy on blood pressure and exercise capacity of individuals with hypertension: a systematic review and meta-analysis/ L.S. Conceição, M.G. Neto, M.A. do Amaral, P.R. Martins-Filho, O. Carvalho // Int J Cardiol. 2016. - Vol. 220. - P. 553-557.

9. Fagard, R.H. Effect of exercise on blood pressure control in hypertensive patients/ R.H. Fagard, V.A. Cornelissen // EurJ Cardiovasc Prev Rehabil. 2007. Vol. 14, №1. - P. 12-17.

10. Is concurrent training efficacious antihypertensive therapy? A metaanalysis / L.M. Corso, H.V. Macdonald, B.T. Johnson, P. Farinatti, J. Livingston, A.L. Zaleski, A. Blanchard, L.S. Pescatello // Med Sci Sports Exerc. 2016. -Vol. 48, № 12. - P. 2398-2406.

11. Physical Activity and Public Health. A Recommendation From the Centers for Disease Control and Prevention and the American College of Sports Medicine // JAMA. - 1995. - Vol. 273, № 5. - P. 402-407.

12. Physical Activity Guidelines Advisory Committee. Washington, DC, US Department of Health and Human Services, 2008. - 683 p.

13. The Physical Activity Guidelines for Americans / K.L. Piercy, R.P. Troiano, R.M. Ballard, S.A. Carlson, J.E. Fulton, D.A. Galuska, S.M. George, R.D. Olson // JAMA. - 2018. - Vol. 320(19). - P. 2020-2028.

14. Xiong, $X$. Effect of baduanjin exercise for hypertension: a systematic review and meta-analysis of randomized controlled trials / X. Xiong, P. Wang, S. Li, Y. Zhang, X. Li // Maturitas. - 2015. - Vol. 80, №. 4. - P. 370-378.

(C) М. Б. Чернова, Г.А. Зайцева, Р.М. Васильева, Н.И. Орлова, 2021 